\title{
SOSIALISMI ON KUOLLUT! KAUAN ELÄKÖÖN \\ MARXILAINEN KAPITALISMI!
}

\begin{abstract}
MEGHNAD DESAI: Marxin kosto. Kapitalismin uusi nousu ja valtiokeskeisen sosialismin kuolema. Gaudeamus 2008.
\end{abstract}

\section{HAAMUN KOSTO}

"Murhansa julma, luonnoton sa kosta." (Haamu $)^{1}$

Aave kummittelee globalisaatiossa - Marxin aave. Kaikki maailman mahdit ja vastamahdit ovat alkaneet jälleen puhua Marxista. Käydessäni taannoin Berliinissä opiskelijat järjestivät Marx-seminaareja ja -bileitä, palattuani lukemaan opiskelijoiden tutkimussuunnitelmia Suomeen silmät ovat pudota päästä, sillä metodina on yhä useammin uusgramscilainen marxilaisuus ellei sitten suoraan historiallinen materialismi. "Sangen kummaa!"2 Marxia tai Gramscia itseään opiskelijat eivät tosin tässäkään Marx-noususuhdanteessa jaksa lukea, mutta miehen nimeä ei enää mainita hiljaisesti ja häveten. Finanssikriisi on jopa herättänyt henkiin jo lopullisesti kuopatuksi uskotut puheet kapitalismin lopullisesta kriisistä, ja nekin, jotka eivät innostu moisista kuolonpuheista näkevät taas politiikan tehtäväksi ainakin kriisiytyneen kapitalismin pelastamisen ja villin finanssikapitalismin uudestaan aisoihin panemisen. Itse kapitalismin luvattu maa kamppailee rahoituslaitosten sosialisoinnin vaatimusten kanssa, ja messiaana tervehdityn Obaman odotetaan pelastavan maailman talous finanssikapitalismin ahneuden aiheuttamilta ongelmilta. Vielä eilen Hayek oli hautaamassa Keynesin johtavana talousideologina ja poliitikot toistelivat maailmanmarkkinoiden välttämättömyyksiin sopeutumista. Nyt kaikki laulavat yh- dessä ääneen kuinka "kolmatta linjaa takaisin näin kuljen. Saa vanhat saatavat jokainen." Kirjoittaessani tätä EU-komissaari Olli Rehn mainostaa Helsingin Sanomissa taas Keynesin yleistä teoriaa talousteorian uutena testamenttina ja katekismuksena. ${ }^{3}$

Vuonna 1988 noususuhdanteensa huipulla oleva Hayek näki jopa liberaalissa keynesiläisyydessä sosialistisen totalitarismin vaaran ja kirjoitti sosialismin kohtalokkaasta ylimielestä jo imperfektissä. ${ }^{4}$ Yhdysvaltalaisten konservatiivien The National Interest -lehdessä Fukuyama julkisti artikkelinsa historian lopusta liberaalin markkinatalouden voittona. ${ }^{5}$ Nyt ollaan jo jonkin aikaa puhuttu "uusliberalismin lopusta" ja johtavat uuskonservatiivit kirjoittavat "historian lopun lopusta".7 Kun Fukuyama esitti teesinsä historian lopusta, itsessään Kojèven hegeliläis-marxilaisen teesiin popularisoidun muunnelman, maailma täyttyi Marx -suhdetta miettivistä seminaareista. Minne Marx oli menossa vai oliko Marx nyt lopulta kuollut ja kuopattu. "Ylevä Caesar kuoli, maaksi muuttui. Ja reiän tukkeeks tuulta vastaan juuttui; Hän, joka säikähdytti maailmaa, Nyt talven myrskyjä saa vastustaa!'8 Kaliforniassa vuonna 1993 järjestetyssä "Whither Marxism" -seminaarissa Jacques Derrida esitti kuuluisan luentonsa, jossa hän pohti Marxin perintöä ja Marx-suhdettaan klassisen murhenäytelmän, Hamletin, kautta. Kommunistisen manifestin kaikkien mahtien jahtaama kommunismin aave oli vaihtunut reaalisosialismin hautausmaalla kummittelevaksi Marxin aaveeksi ja marxilaisten ahdistukseksi. "Ollako vai ei olla, siinä pulma." Derrida halusi kuitenkin mie- tiskellä Marxin jäännöksiä: "Voi, Marx parka! - Minä tunsin hänet... äärettömän sukkela, erinomaisen leikillinen mies; hän on selässään minua kantanut senkin tuhannen kertaa." 10 Derridan mukaan maailmassa oli edelleen paljon "mätää" eivätkä nuoren Fukuyama-Fortinbrasin voittoisat eskatologiset torven toitotukset Marxin haudanneesta "ilosanomasta" olleet hänelle mieleen vaan hän halusi vastata vetäytyvän haamun vaatimukseen. " $H y$ västi, Hamlet, hyvästi! Mua muista!"11 Althusserista asti Marxin taustalla seissyttä Hegelin haamua purkanut ranskalainen ajattelu ei voinutkaan olla närkästymättä liberaalin hengen uudelleen lämmittämästä jäännöksettömästä teleologisesta historianfilosofiasta. Derridalle närkästyksen tarkoitus ei ollut kuitenkaan herättää Marxia henkiin tai lähteä kostoretkelle, vaan lukea Marxin muiston moninaisten haamuilujen heterogeenisia jälkiä, eli kuten Derrida Marx kirjansa lopetti: "Lukenut mies, Horatio, puhu sille."12 1990-luvulla Marxin haamu ilmaantuikin lähinnä Hamletin viidennen näytöksen hautausmaakohtauksen melankolisessa ilmapiirissä, kun taas 2000-luvulla haamun sotahaarniskan sisään on ahdettu "kiireestä kantapäähän"13 nuorta lihaa ja verta.

Mielenkiintoinen tapaus näissä Marxin suhdannevaihteluissa on nyt suomeksi ilmestynyt, mutta jo ennen uutta aktiivisempaa Marx-innostusta ja nykyistä finanssikriisiä kirjoitettu Meghnad Desain teos Marxin kosto. Suomessa syksyllä käväissyt intialaissyntyinen Lordi Desai on Britannian parlamentin ylähuoneen jäsen ja London School of Economicsin emeritusprofes- 
sori, mutta ei emmi ilmoittaessaan Marxin henkiseksi isäkseen ja vieläpä panee "vetoa tuhat puntaa haamun sanain totuudesta". ${ }^{14}$ Desaille tuhannet maailmalla kiertävät punnat osoittavat nimittäin Marxin olleen oikeassa yhteiskunnallisen astronomian osalta. Ja jos saan käyttää edelleen Hamlet-analogiaa, ei Desai emmi myöskään isän haamun vaatiman koston edessä vaan on nimennyt kirjansa suoraan Marxin kostoksi.

\section{MURHANHIMOINEN PETOS}

"Tuon valheellisen tiedon kautta häijyst' / On petetty; mut, jalo nuorukainen, / Se käär me, joka hengelt' isäs pisti, Nyt kantaa kruunua." (Haamu)

Hamletin tavoin Desain kostodraamassa on myös kyse sukurutsaisesta ja murhanhimoisesta isän perinnön ja kruunun anastamisesta. "Voittonsa nojalla bolsevikit ottivat haltuunsa Marxin ja vartioivat siitä pitäen ärhäkkäästi, suorastaan murhanhimoisesti yksinoikeuttaan hänen perintöönsä" (mt., 20). Bolsevikit ja heidän muualla riehuneet serkkunsa, kuten Desai leninismin eri muotoja nimittää, saavat näytellä tässä draamassa Glaudiuksen roolia. "Se sukurutsa, haurelias peto. Älynsä tenholla ja konnantaidollaan ... sai puolisoni." ${ }^{5}$ Desai ei kaihdakaan syyttämästä reaalisosialismia ihmisten murhaamisesta ja orjuuttamisesta, mutta haluaa vapauttaa Marxin tämän nimissä tehdyistä "sanoin kuvaamattomista rikoksista". (Mt., 378.) Tässä ei ole mitään uutta. Jo Marx halusi vapauttaa itsensä marxilaisista ja suurin osa marxilaisista on halunnut vapauttaa itsensä reaa- lisosialismin vähemmän kunniakkaista aikaansaannoksista. Varsinainen uusi juonenkäänne Desainin kostodraamassa on kuitenkin väite, että juuri kapitalismin voittokulku on Marxin kosto Leninille. "Minä väitän, että kapitalismin uusi mahti - ja etenkin sen ulottuminen koko maailmaan - osoittaa kaikista ajattelijoista juuri Marxin olleen oikeassa" (mt., 21). Eikä tässä suinkaan kaikki. Nimittäin taloustieteilijä Desain draamassa Hamletin rooli näyttää lankeavan Friedrich Hayekille, kun taas Keynes ja Schumpeter saavat näytellä eräänlaiset Rosencranzin ja Gyldensternin osat.

Desain mukaan "Marx kuuluu niihin, jotka antavat talouden johtamisen mieluummin markkinoiden kuin valtion tehtäväksi” (mt., 21) ja joille "kapitalismin esteetön kehitys oli parempi vaihtoehto kuin taantumuksen voitto" (mt., 373). Desai puhuukin kapitalismin marxilais-hayekilaisesta kuvauksesta, jonka katsoo vastaavan sen yleistä kehitystä. Kuvatussa kehityksessä on kyse siitä, kuinkakapitalismi kostaa bolsevikeille näiden luonnottoman isänmurhan - sen tekijät eivät tavoittaneet kapitalismin luonnollisia lakeja yhtä hyvin kuin sen varsinaiset astronomit Marx ja Hayek. Hayek tekikin aikoinaan Desaihin nuorena marxilaisena lähtemättömän vaikutuksen London School of Economicsissa, kuten tämä edelleen pirteä emeritusprofessori kertoi tämän arvostelun kirjoittajalle kaljatuoppien ääressä. Ja kun kirjoittaja sanoi, että tämä Marxin ja Hayekin naimakauppa oli hänelle vaikeimmin sulatettavaa antia kirjan argumentaatiossa, emeritus nauroi syvältä vatsastaan todeten, että niinhän ne kaikki sanovat.

Keynesin Desai vuorostaan liittää enemmän Hegelin perintöön, joka lähinnä voi esittää kapitalismille varauksia. "Kapitalismi vastaa yleensä marxilais-hayekilaista kuvausta, mutta osoittaa ajoittain keynesiläis-hegeliläiset varaumat aiheelliseksi" (mt., 363). Desai tunnustaa kuuluneensa itse Keynesin leiriin, kunnes ymmärsi marxilais-hayekilaisuuden ylivoiman. Näin on varsinkin avoimessa globalisaatiossa, josta ei ole enää mahdollista palata niin sanotun "Keynesin aikakauden" kansallisen kapitalismin kultakauteen. "Hänen kukkaronsa on jo tyhjä: kaikki kultaiset sanat on kulutettu." Sen romantisointi on Desain mielestä turhaa sekä taantumuksellista länsimaiden protektionistista itsesuojelua globaalin köyhyyden edessä. Desai allekirjoittaakin uusliberalistisen (Desaille tosin marxilaisen) ajatuksen kapitalismista köyhyyden voittajana ja kurjuuden poistajana, tosin schumpeterilaisella luovalla tuholla lisättynä. "Kapitalismi on paras järjestelmä köyhyyden ja kurjuuden lieventämiseksi, vaikka järjestelmä itse tuhoaakin työpaikkoja ja pakottaa kansantaloudet rakenneuudistuksiin” (mt., 366). Keynesiläisyyttä Desai taas sanoi Suomessa käydessään pitävänsä cambridgeläisenä elitisminä tai "Bloomsburyn ryhmän" hengen mukaisena ylimielisenä asenteena, jossa ajatellaan valveutuneen eliitin voivan hallita maailman taloutta ja selvittää sen ongelmat. Se voi kuitenkin enää toimia vain länsimaiden onnettomana yrityksenä säilyttää ylivalta Kiinan, Intian ja koko Aasian edessä. Kirjassaan Desai katsookin Keynesin jo menneen talven lumeksi eikä laula mui- 
takaan kolmannen tien lauluja vaan suosittaa myös finanssikriisiin marxilais-hayekilaista kapitalismin itsehoitoa. "Jos uskot vakavasti vapaisiin markkinoihin niin annat niiden toimia vapaasti ja korjata itsensä. Älä syötä sitä vaan näännytä se nälkään. Älä eristä sitä shokeilta vaan altista se, jotta siitä tulee elinvoimaisempi. Tämä olisi Marx-Hayekin viesti." ${ }^{16}$ Tosin Suomessa Desai uskaltautui jopa spekuloimaan koko finanssijärjestelmän eräänlaisella globaalilla sosialisoinnilla ja valvonnalla. Tämäkään ei tarkoittaisi kapitalismin loppua vaan ennemmin hegeliläis-keynesiläisiä varauksia hieman laajemmassa mittakaavassa.

Loppujen lopuksi kapitalismi itsessään on Desaille kuin joustava hoviherra, ei tosin surmansa saava Polonius, vaan historian myrskyistä aina selviävä kyyninen opportunisti Talleyrand. "Kapitalismi voisi aivan hyvin ylpeillä saavutuksistaan samoin kuin Talleyrand ansioistaan Ranskan vallankumouksessa: 'Minä säilyin hengissä’” (mt., 363).

KAPITALISMIN

DYNAMIIKKA

"Äl' ijäti, noin silmät maassa, kallist' Isääsi mullast' etsi. Kellä henki, - Se jokapäiväistä, - sen hauta vie, Ja kuolon kautt' on ijäisyyteen tie." (Kuningatar ${ }^{17}$

Desaille kapitalismi on schumpeterilaisesti dynaaminen ja kriisien kautta etenevä järjestelmä, jossa tapahtuu jatkuvasti tuhoa ja uutta luomista. Juuri tämän ymmärtämisessä piili Marxin suuruus: "Adam Smithin jälkeen vasta hän teki vakavan yrityksen ymmärtää kapitalismin dynamiikkaa. Sen koommin kukaan ei ole onnistunut siinä tehtävässä, joskin Schumpeter pääsi lähelle." (S.17.) Schumpeterille kapitalismi ilman luovaa tuhoa olisikin "kuin Hamlet ilman Tanskan prinssiä". ${ }^{18}$ ja Desaille Schumpeterin ansio oli kapitalismin dialektinen tarkastelu sekä hyvässä että pahassa sekä kommunistisen manifestin lausuman "kaikki [...] pysyväinen haihtuu utuna ilmaan"19 ymmärtäminen. Schumpeterin Taloudellisen kehityksen teoria on "huolellinen ja yksityiskohtainen vastaus Marxin kysymykseen voittojen alkuperästä [...] Hänen mukaansa voitot eivät synny työn riistämisestä vaan innovaatioista." (S. 218.) Desaille kapitalismi on "voiton tavoitteluun perustava pääoman kasaantumisen ja tuottavuutta parantavien uusien valmistusmenetelmien päättymättömän etsinnän järjestelmä. Järjestelmässä voi sen perusominaisuuksien vuoksi herkästi ilmetä suhdannevaihteluita, romahduksia ja paniikkeja." (Mt., 366.)

Mutta kun Schumpeter diagnosoi sosiologiselta kannalta kapitalismin mahdollisen ylittämisen, niin Desai vetoaa juuri historialliseen materialismiin kieltäessään tämän tai pikemminkin työntäessään sen hamaan tulevaisuuteen. "Väistämättömyyteen ei liity mitään aikataulua. Asia on samanlainen kuin Kristuksen toinen tuleminen. (Mt, 112.) Desain luennassa historiallinen materialismi muuttaa nuoren kumousta saarnaavan eskatologisen Marxin kypsäksi kumouksen lykänneeksi ja kapitalismia tutkivaksi teologi Marxiksi. Desaille Marxin teoria ei ole vallankumouksen vaan taloudellisten kumousten teoria. "Se on alkuaan tarkoitettu kapitalismin liikelakien tutkimiseen, järjestelmän vahvuuksien ja rajoitusten selvittämiseen" (mt., 69). Tässä Desai vetoaa juuri vuoden 1859 Kansantaloustieteen arvostelua (Zur Kritik der Politischen Ökonomie) teoksen esipuheen historiallisen materialismin perusesitykseen, jossa Marx toteaa: "Mikään yhteiskuntamuoto ei häviä ennen kuin kaikki sen puitteisiin mahtuvat tuotantovoimat ovat kehittyneet, eikä uusia korkeampia tuotantosuhteita tule tilalle ennen kuin niiden aineelliset olemassaolon ehdot ovat varttuneet vanhan yhteiskunnan omassa sylissä." ${ }^{20}$ Desain tulkinnan mukaan Marx siis väitti kapitalismin selviävän siihen asti kunnes kapitalistisen tuotannon kaikki mahdollisuudet on käytetty, ja koska näin ei ole vielä tapahtunut, on juuri historiallisen materialismin mukaan sopeuduttava kapitalismiin.

"Ei ole näköpiirissä sellaista uutta tuotantotapaa, joka voisi korvata kapitalismin. Täytyy vain sopeutua siihen, että kapitalismi on kerta kaikkiaan vallitseva järjestelmä." (Mt., 365.)

Mitä taas tulee sosialismin toimivuuteen, niin Desai liittoutuu Hayekin puolelle myös niin sanotussa "sosialistisen laskennan kiistassa", jota Ludwig von Mises ja Otto Neurath olivat käyneet tasapainomallin kehikossa, mutta jonka Hayek siirsi tasapainoongelmasta keskittämisen ongelmaan. Jälleen Desai väittää Hayekin olleen tässä sosialismin kumoamisessa samaa mieltä itse Marxin kanssa ja kritisoi sosialisteja Marxin ja Hayekin ajattelun hylkäämisestä:

"Unohdettiin Marxin ja Hayekin kannattama ajatus, jonka mukaan kansantalous 
on itseään ohjaava kehityskulku, jossa miljoonat yksilöt toimivat paikallisen tietämyksensä pohjalta ja pyrkivät lakkaamatta parantamaan asemaansa. Olennaista ei ole se, että sosialistinen suunnittelija ei kykene ratkaisemaan kaikkia tarvittavia yhtälöitä. Olennaista on se, että kaikkea tietoa on viime kädessä mahdotonta keskittää. Sitä paitsi tiedon keskittäminen on tehotonta, äärimmäisen tehotonta." (S. 243.)

Marxin haamu olisi siis kannustanut Hayekia tämän kiistassa Wienin piirin rationalistimarxilaisten kanssa.

Entäpä sitten sosialismi tai kommunismi? Halusiko Marx todella unohtaa nämä kapitalismin nimissä? Ensinnäkin Desai korostaa, että Marxille kapitalismin ylittävässä sosialismissa taloutta ja tuotantovälineitä ei ota haltuunsa valtio kuten valtiososialismissa vaan yhteiskunta, globaalissa kapitalismissa haltuunottajan täytyisi siten olla globaali yhteiskunta. Toiseksi Desai korostaa yhä uudestaan kuinka Marxille siirtyminen sosialismin kautta kommunismiin oli mahdollista vasta kun edistyksellinen kapitalistinen tuotantojärjestelmä on saavuttanut rajansa ja mahdollisuutensa ja muuttunut taloudellis-tuotannollisesti taantumukselliseksi. "Kapitalismi on kehittynyt aidosti maailmanlaajuiseksi eikä silti ole vielä saavuttanut rajojaan" (s. 378). Desain mukaan Marx itse "haukkui pataluhaksi aikansa sosialistit, jotka elättelivät kuvitelmia sosialismista" (s. 373). Marx kannattaisi globaalia vapaakauppaa ja näkisi kaikki sen rajoittajat taantumuksen edustajina. Loppujen lopuksi Marx ei koskaan esittänyt mitään selvää suunnitelmaa tai analyysia sosialistisesta tai kom- munistisesta siirtymästä vaan varsinkin "kypsällä kaudellaan" keskittyi vallitsevan tuotantojärjestelmän, kapitalismin, tutkimiseen. Marxin "kansanomainen versio on peräisin juuri Kommunistisesta manifestista", jonka Marx kirjoitti "kiihkeässä nuoruudessaan" (mt., 107). Pääoma sen sijaan on: "kriittinen tutkimus siitä miten kapitalismiksi nimitetty tuotantotapa toimii [...] Pääoma ei sisällä yhtään sellaista kapitalismin dynamiikkaa käsittelevää kertomusta, jossa ennustetaan järjestelmän aikanaan sortuvan." (MT, 108.)

Althusserin tavoin Desai haluaa siis hylätä nuoren idealistisen Marxin kypsän "tieteellisen" Pääoman Marxin hyväksi ja kieltää historiallisen materialismin mekaanisen tai teologisen tulkinnan. Mutta kyse ei ole althusserilaisesta humanisti-Marxin hylkäämisestä dialektisen materialismin teoreettis-tieteellisen politiikan nimissä vaan Marxin nuoruuden idealistisen politiikan hylkäämisestä teoreettis-ekonomistisen tulkinnan nimissä. 60-luvun Althusserille Desain tulkinta olisi siis porvarillis-ideologinen mystifikaatio eikä "tieteellinen", kun taas Desai haluaa vapauttaa Pääoman taloustieteellisen tulkinnan sen poliittis-ideologisista mystifikaatioista. Ja siinä missä Althusserille "Pääoman ymmärtämiseksi [...] on välttämätöntä omaksua proletariaatin luokka-asema", ${ }^{21}$ on Pääoman ymmärtäminen markkinatalouden ilosanomaksi nostanut Desain ylähuoneen lordiksi. Koska Desaille Pääoma ei ole poliittinen vaan taloustieteellinen kirja ja Marxin suuruus piilee tämän kapitalismin taloudellisen astronomian tutkimuksessa, hän voikin asettaa Schumpeterin, Key- nesin ja lopulta ennen kaikkea Hayekin Marxin taloustieteellisen perinnön, Adam Smithiltä perityn yhteiskuntaastronomian, paremmiksi vaalijoiksi kuin erilaiset marxilaisuuden poliittiset muodot.

Desai kritisoikin Marxin näkemistä jonkinlaisen tieteellisen politiikan profeettana ja varoittaa etsimästä tältä mitään pseudohistoriallisia lakeja. Ja kuitenkin samalla hän kritisoi poliittisia liikkeitä, jotka eivät ota huomioon Smithin ja Marxin esittämää talouden astronomiaa. Valtio-oppinut, jonka ammatillisesti pitää olla huolissaan politiikan puuttumisesta, on tästä argumentaatiosta hieman hämmästynyt. Muutaman lisäoluen jälkeen hän ei voi ollakaan kysymättä hymyilevältä Buddhalta näyttävältä Lordi Messailta miten yhteiskunta-astronomiassa voi olla mitään paikkaa politiikalle? Pirteästi hymyilevä Lordi vakavoituu hetkeksi ja katsoo sitten kysyjää silmiin tiukasti lausuen: "Olet aivan oikeassa, aivan oikeassa, juuri niin, yhteiskunta-astronomiassa ei ole tilaa politiikalle ja politiikka, politiikka, se on kyllä tärkeää, hyvin tärkeää.” Mietin hetken onko tässä kyse ristiriidat ylittävästä korkeammasta tietoisuudesta vai kenties vain ylähuoneen Lordin sulavasta käytöksestä pientä valtio-oppinutta kohtaan. Mutta kyse taitaa olla vain yksinkertaisesti klassisesta talouden ja politiikan alueiden eristämisestä autonomisiksi alueiksi, jossa politiikka ei saa puuttua materiaaliseen talouden astronomiaan, mutta on tärkeää taloudesta eristetyn kulttuurin teatraalisena representaationa. Ei kenties ole ihme, että elokuvia rakastava Desai pitää merkittävimpänä teoksenaan ihailemastaan Bolly- 
wood-sankarista Dilip Kumarista kirjoittamaansa teosta "Nehrun sankari Dilip Kumar Intian elämässä" ${ }^{22}$ Nehrun talouspolitiikkaa Desai ei enää kiitä vaan näkee sen tuloksena "brittien snobistisesta ylenkatseesta rahaa ja kaupankäyntiä kohtaan" (mt., 286) ja Nehrun omaksumasta yksinkertaistettujen uskonkappaleiden alkeellisesta marxismista. Sen sijaan Bollywoodin globaali Hollywoodin haastava menestys on Desaille hyvä esimerkki teollisuuden menestyksestä, jos se saa kehittyä erossa poliittisesta ohjauksesta. $^{23}$ Niinpä kun olemme yhdessä lordin kanssa todenneet politiikan tärkeäksi, alamme puhua intialaisista elokuvista, vaikka olenkin hieman paitsiossa Bollywoodin globaalista menestyksestä.

Kirjassa kuitenkin poliittinen toiminta kapitalistisen astronomian ohjaamiseksi, muuttamiseksi tai pysäyttämiseksi näyttää olevan se varsinainen Glaudiuksen rikos, johon Marxin nuoruuden kirjoitukset liian vakavasti ottavat syyllistyvät. Kapitalistisen globalisaation vastustajia, jotka haluavat liittoutua kolmannen maailman talonpoikien kanssa kapitalismia vastaan, Desai vertaa narodnikkeihin, jotka halusivat vastustaa kapitalismin toimintaa kaikin keinoin. "Marxilaiset eivät hyväksyneet sellaista toimintaa vaan katsoivat narodnikkien päättelyn virheelliseksi" (mt., 133). Tässä suhteessa Desai ylistää jopa Leniniä, joka kritisoi narodnikkeja taloudellisesta romantismista ja muistuttaa kuinka nuori Lenin tuki vapaakauppaa tuotantovoimia lisäävänä tekijänä. Vasta "kypsä" Lenin sortui ajamaan kapitalistisen järjestelmän epäkypsää ylittämistä. Siinä missä nuori Lenin ja kypsä Marx ymmärsi- vät kapitalismin edistyksellisyyden, nuori Marx ja kypsä Lenin elättelivät turhia toiveita sen poliittisesta ylittämisestä.

Desai hylkää aaveiden poliittiset manifestit haaveellisina profetioina. Kommunistisen manifestin kuvaus kapitalismista kaiken mullistavana edistyksellisenä järjestelmänä on oikea, mutta siihen pesiytynyt kommunismin aave sai aikaan vain painajaisia.

"Euroopassa kummitteli läpi 1800-luvun mahdollisuus sortovallan joutumisesta sorrettujen kukistamaksi. Pitkäksi venyneen 1800-luvun (18151914) päätteeksi painajainen toteutui." (Mt., 20.)

Bolsevikkien synti oli yrittää poliittisesti luoda yhteiskuntajärjestelmä, johon ei ollut todellisia marxilaisia taloudellisia perusteita. Kuten Desain Suomessa ollessaan totesi: "Venäläiset talonpojat kaappasivat Marxin ja marxilaisuus jäi lähes vuosisadaksi näiden vangiksi."

Täysin vastakkaisesti provokatiivinen "Leninin" lukija, Slavoj Zizek, on taas vaatinut juuri Leninin "epäkypsän", taloudellista edellytyksistä välinpitämättömän poliittisen eleen toistamista nyt kun Wall Streetin sijoittajat ovat kaapanneet Marxin.

"Marx on OK, jopa Wall Streetillä on tänä päivänä Marxia rakastavia ihmisiä - hyödykkeiden runoilija Marx, joka tuotti täydellisiä kuvauksia kapitalistisesta dynamiikasta, kulttuuritutkimuksen Marx, joka esitti nykypäivän vieraantumisen ja esineellistymisen, - mutta, Lenin, ei, et voi olla vakavissasi. Työväenliike, vallankumouksellinen puolue ja vastaavat zombie-käsitteet. Eikö Lenin edusta juuri marxismin käytäntöön soveltamisen EPÄONNISTUMISTA， suurta katastrofia, joka jätti jälkensä koko viime vuosisadan maailmanpolitiikkaan, reaalisosialistista koetta, joka kulminoitui taloudellisesti tehottomaan diktatuuriin." 24

Zizekin mukaan tämä toistaminen ei merkitsisi paluuta kuopatun Leninin epäonnistuneisiin saavutuksiin vaan ehdottaa tuota nyt epäajanmukaiseksi nähtyä poliittista elettä juuri noiden epäonnistumisten hukkaamien mahdollisuuksien tähden. ${ }^{25}$ Tämä olisi Zizekille ainoa toimiva tapa heikentää globaalin liberaali-kapitalistisen maailmanjärjestyksen totaalisuutta, johon Zizekin mukaan erilaiset aikamme antikapitalistiset humanistis-idealistiset poliittiset liikkeet eivät kykene. Valtio-oppinut ei voi olla kuitenkaan miettimättä ovatko nämä kaksi täysin vastakkaista provokaatiota sittenkin eräällä lailla toistensa peilikuvia.

\section{KOSTON DRAMATURGIA}

"Kappale, toimintaan katsoen hyvin järjestetty ja yhtä suurella maltilla kuin taidolla tehty[... ]

Jos kuningas ei näytelmätä kiitä, / Niin luulen, että hän ei pidä siitä.

Soittoa, soittoa!" (Hamlet)

Desain hayekilaisesta marxismista voi tietenkin olla monta mieltä, mutta kirja on ehdottomasti lukemisen arvoinen ihan juonenkuljetuksensa ansiosta. Se ei ole hankala tutkimusdraama vaan onnistunut popularisointi, helposti luettava viihdyttävä viikonloppuillan draama, josta puuttuvat kesäteatterin noloimmat hetket. Se etenee sujuvasti ja viihdyttävästi yhdistäen historiallisia tapahtumia, talousteoreettisia pohdintoja 
ja yleisiä kulttuurisia ja poliittisia huomioita. Tältä osalta voi yhtyä Juhana Vartiaisen lievetekstin toteamukseen kirjasta "hienona jännitysnäytelmänä, jossa palaset asettuvat toisiinsa loogisesti”.

Tosin välillä tuo palasten liiankin helppo loksahtaminen alkaa hieman tympiä, ja teos muistuttaa paikoitellen kliseemäistä Bollywood-draamaa. Sinänsä sujuvasti kerrotussa tarinassa ei nimittäin ole mitään kovin yllättävää tai erikoista lukuun ottamatta tuota suurta juonenkäännettä, jossa kapitalismin voittokulun oikeuttajana toimii itse Marxin haamu Hayekissa ruumiillistuneena. Ja vaikka teos heijastelee mielenkiintoisesti Desain oman ajattelun historiallista ja taloustieteellistä muutosta, se on kirjoitettu tämän Hayek-kääntymyksen jälkeisestä näkökulmasta, ja näin tarinaa ohjaa näkymättömän käden kaitselmuksen viisaus, aivan kuten Augustinuksen Tunnustuksien uusi kristillinen jumala seurasi isällisen lempeästi Augustinuksen aikaisempia harhaoppeja. Ateistiksi julistautuneen Desain retoriikassa kaikki hayekilaisesta Marxista poikkeavat tulkinnat tyrmätäänkin jatkuvasti uskonnollisena marxismina, kun taas Hayek esitetään syrjittynä totuuden torvena, jonka varjelemana Marxissa itses- sään piillyt totuus saa lopulta tunnustuksen ja Haeyk paljastuu Marxin oikeaksi pojaksi. Sekulaaria järkeä korostavan Desain oma retoriikka muistuttaakin paikoin stereotyyppistä uskonnollisen käännynnäisen argumentaatiota. Tässä suhteessa Desain hayekilainen marxismi voisi olla uskontotieteellisesti kiinnostava ilmiö, yhdistäähän se kerralla marxilaisen ja uusliberalistisen uskon. Jälkimmäinenhän on saanut monet lähes uskonnollisesti sosialismia ennen saarnanneet sittemmin kääntymään yhtä innokkaiksi puhtaan markkinakapitalismin profeetoiksi. Valtio-oppinut pohtii, onko taloustieteilijöillä yleisesti jokin "uskonnollinen elin", joka voisi kenties myös selittää miksi taloustieteilijät ovat ottaneet sekulaarissa maailmassa vanhan papiston roolin. "Mutta asia, hyvä herra? Miksi tuota ylimystä sokaisemme karkealla hengellämme?"

Mutta jos ei anna uskonnollisen sävyn vaivata sen enempää kuin luettaessa Augustinuksen Tunnustuksia, niin kirja on erittäin sujuva ja mielenkiintoinen. Selkeän esityksensä osalta se voisi toimia jopa hyvänä oppikirjana, jos vain opiskelijat jaksaisivat muistaa, että tällaisissa vahvoissa tarinoissa on aina kyse yhdestä tulkinnasta. Sen "marxi-

\section{vi it te et}

1. Hamlet, I Näytös, 5. Kohtaus.

2. Hamlet, I Näytös, 1. kohtaus.

3. Olli Rehn, "Kuka hidastaisi kyytiä?" Helsingin Sanomat 3.3.2009.

4. Friedrich A. Hayek, Kohtalokas ylimieli. Gummerrus: Art House, 1998.

5. Francis Fukuyama, "The End of History?" The National Interest, Summer 1989. Ks. myös kirja Fukuyama, Francis, Historian loppu ja viimeinen ihminen. Juva: WSOY, 1992.

6. Joseph E. Stiglitz, "The End of neoliberalism". New Europe. 21.6.2008: 791 .

7. Ks. Robert Kagan, "The End of the End of History". The New Republic 23.4. 2008.

8. Hamlet, I Näytös, 5. Kohtaus.

9. Hamlet, III Näytös, 1. Kohtaus.

lainen uusliberalismi" myös mukavasti sekoittaa erilaisia onttoja ja stereotyyppisiä käsityksiä "uusliberalismista" tai "marxilaisuudesta". Adam Smith, Marx tai Hegel -tutkijat varmasti hermostuvat joistain yleistyksistä, ja myös historiantutkijat voivat paikoitellen repiä hiuksiaan, mutta taloustieteilijän kirjoittamaksi historiallis-taloudelliseksi katsaukseksi kirja on mielenkiintoinen ja myös taloustieteellisesti yleissivistävä ja opettava. Gaudemuksen julkaisema käännös on myös sekä ulkoasultaan ja taitoltaan hienompi ja fyysisesti mukavampi lukea kun alkuperäinen englanninkielinen teos. Samoin Timo Soukolan käännös on sujuva, jos unohdetaan muutamat lipsahdukset, kuten Adam Smithin kuuluisan nuppineulatehtaan vaihtuminen käännösprosessissa naulatehtaaksi.

Lopuksi pitää myös todeta, että ainakin Desai on johdonmukainen hayekilaisessa marxismissaan, sillä jos uskotaan vapaiden markkinoiden itseään parantavaan voimaan ja nousukaudella yksityistetään julkisia varoja, ei sitten pitäisi taas laskukaudella huutaa julkista valtaa pelastustöihin ja kuitenkin "tahtomme ja sallimuksen tie. Useinkin vastakkaiseen suuntaan vie".

Markku Koivusalo

10. Hamlet, V Näytös, 1. kohtaus 11. Hamlet, V. Näytös,

12. Hamlet, I. Näytös,

13. Hamlet, I Näytös, 1. Kohtaus.

14. Hamlet, III Näytös, 2. Kohtaus

15. Hamlet, I Näytös, 1. Kohtaus.

16. Desai, "The Marx-Hayek solution to the crisis". Financial Express. Monday, October 06, 2008.

17. Hamlet, II Näytös, 1. Kohtaus. 
18. Ks. Schumpeter: "Luovan tuhon prosessi". Tämä numero.

19. Kommunistinen manifesti.

20. Karl Marx, Kansantaloustieteen arvostelua. Helsinki: Kansankulttuuri Oy, 1970, 18.

21. Louis Althusser, "Preface to Capital Volume One". Teoks. Althusser, Lenin and Philosophy and Other Essays. New York: Monthly Review Press, 100.

22. Meghnad Desai: Nehru's Hero Dilip Kumar in the Life of India. New Delhi, Roli Books, 2004

23. Ks. Haastatelu 12/07/00. Official Commanding Heights Site at PBS (High-Bandwidth).

24. Slavoj Zizek: Repeating Lenin. Arkzin 2002,

25. "Leninin toistaminen ei tarkoita sen toistamista mitä Lenin TEKI; vaan sen mitä hän EPÄONNISTUI TEKEMÄÄN; hänen HUKKAAMIENSA mahdollisuuksien toistamista." Mt. 